\title{
Literature Review in Preparation for Professional Life of the People with Developmental Disability
}

\author{
Keoung Yeol Kim ${ }^{1}$ \\ ${ }^{1}$ Associate professor, Department of social welfare, Young San University, South Korea, \\ 007powerk3@gmail.com
}

\begin{abstract}
In terms of academic understanding to support the professional life and independent life of the developmentally disabled people, this study is aimed to answer the following research questions. First, what is the concept of developmental disability? Second, why is the professional life necessary for the developmentally disabled person? Third, what is the independent living support model for people with developmental disabilities? This study focused on domestic and foreign literature and related reports on the professional life of persons with developmental disabilities. In detail, the research purpose was achieved by dividing the thesis into degree claim thesis, other research thesis, and policy report by the researcher to read, organize and analyze the contents. The main findings of this study and implications are : First, developmental disabilities are those who have neurological conditions closely related to intellectual disabilities such as intellectual disability, cerebral palsy, epilepsy, autistic disabilities, learning disabilities, or have problems that require education and training similar to those required for intellectual disabilities. Second, for people with developmental disabilities, the meaning of professional life is meaningful as a means to lead an independent life in society or as a means of expressing the value of one's existence. Third, in order to understand the professional life of workers with developmental disabilities, it is necessary to understand the background of the emergence of the social model and the independent living support model. The interest of social model is not to make the problem of the social system that alienated the disabled from the main environment.
\end{abstract}

Keywords: Social Welfare for the Disable, Social Welfare, Job Rehabilitation, Special Education

\section{Introduction}

\subsection{Necessity of Research}

According to the registration status of persons with disabilities, among the total registered persons with disabilities, 195,283 persons, or 7.78\%, out of 2,511,051 persons with disabilities, and 22,853 persons with autism, or $0.91 \%$ (Ministry of Health and Welfare, 2016). In addition, according to the employment status by type of disability by the Korea Employment Development Institute for the Disabled[1], 'disability' accounted for $45 \%$ of the external disability, accounting for the highest proportion. And 'visual impairment' was 42.9\%, 'hearing impairment' 33.3\%, 'language impairment' $28.6 \%$, 'intellectual disability' $24 \%$, and 'autistic disorder' $17.49 \%$. This shows that the employment rate of persons with developmental disabilities is still low compared to those with physical and sensory disabilities.

Because people with developmental disabilities receive 'alienation and discrimination' instead of 'prior

*This study was revised and completed from the 2018 doctoral thesis.

Received: March 31, 2021; 1st Review Result: May 14, 2021; 2nd Review Result: June 28, 2021

Accepted: July 31, 2021 
attention and consideration' from society, they have been reduced to economically disadvantaged people deprived of their social status. For people with developmental disabilities, our society tends to perceive them as 'dependent beings' as objects receiving services rather than as subjects of choices and decisions [2]. This is the result of failing to break away from the position of the rehabilitation paradigm, which sees the disabled as the subject of the problem because they focus on physical damage and lack of vocational skills. If the continuous support of an appropriate environment suitable for them and the removal of social barriers are carried out at the same time, they will be able to position themselves as consumers and parties with better self-reliance. For people with developmental disabilities, professional life is a pathway through which they can expand beyond economic independence to psychological and social independence. Therefore, a lot of attention and effort are needed for the developmentally disabled to stand as independent beings through their professional life.

As a result of discriminatory gazes and reactions to people with developmental disabilities working in community job sites instead of social support, the phenomenon of being separated from job sites is increasing. Therefore, in order to reduce the number of people with developmental disabilities who fail to maintain their professional life after entering the profession and drop out midway, more concrete efforts are needed for the professional life of workers with developmental disabilities. In particular, sufficient consideration and effort are required to improve the quality of life of persons with developmental disabilities, who are members of the local community, through job security in terms of social welfare. Existing studies have less systematically organized theories about developmental disabilities and the professional life of people with developmental disabilities. A literature review study is necessary to provide effective support to the developmentally disabled in the reality that they lack an understanding of the concept of developmental disability and the need for professional support. The purpose of this study is to examine the concept of developmental disability and the meaning of occupation for people with developmental disabilities through domestic and foreign literature written on the topic of professional life of people with developmental disabilities.

\subsection{Research Problems}

This study is aimed to answer the following research questions from the prospective of academic understanding to support the professional life and independent life of persons with developmental disabilities. First, what is the concept of developmental disability? Second, why is the professional life of persons with developmental disabilities necessary? Third, what is the independent living support model for the developmentally disabled?

\section{Methodology}

In order to prepare an institutional device to guarantee the professional life of persons with developmental disabilities, it is necessary to understand various documents related to the occupations of persons with developmental disabilities. This study focused on domestic and foreign literature and related reports on the professional life of persons with developmental disabilities. In detail, the research purpose was achieved by dividing the thesis into degree claim thesis, other research thesis, and policy report by the researcher to read, organize and analyze the contents. From 2001 to 2020, studies on preparation for professional life of persons with developmental disabilities were analyzed. First, data were obtained by computer search for papers from 1995 to 2004 with search terms such as developmental disabilities, occupational life of persons with developmental disabilities, and occupations of persons with disabilities. Second, the research results were derived by examining the theoretical concepts of the selected papers. 


\section{Contents}

\subsection{Developmental Development}

"Developmental development" refers to changes in physical or psychological functioning from conception to death. In this process, functional limitations may appear due to various causes. A developmental disability is defined as "mental, physical, or both present before the age of 22, which persists indefinitely and results in substantial functional limitations in three or more areas of life activity (personal processing, language, learning, mobility, self-management, independent living, and economic self-sufficiency). It is a severe and chronic disability caused by [3]. The American Association on Intellectual and Developmental Disabilities (AAIDD)[4] defines developmental disability as a severe, chronic disability that can be manifested by cognitive and physical causes. Developmental disability refers to a disability in which development significantly deviates from the average, resulting in severe and chronic disability in physical, mental, or both domains. Developmental disabilities were defined in the following five categories[5]. First, it is caused by mental or physical damage or by mental and physical overlapping disorders. Second, it appears before the age of 22. Third, it appears vaguely and continuously. Fourth, there are three or more functional restrictions in the following main life activity areas (1. personal processing, 2. verbal expression or cognitive ability, 3. learning, 4. athletic ability, 5. self-supervision, 6. independent living ability, 7. economic ability). . Fifth, it requires special internal training or general protective treatment and individually planned lifelong continuing education[5].

According to [6] in terms of the scope of developmental disabilities, from the opinion that 'not only sensory disorders are excluded, but only severe cases among other disorders are included in developmental disorders' It is said that the difference in understanding is very large, even to the opinion that it covers all disability states that occur. In other words, depending on the concept of developmental disability, the areas of disability included are diverse. The United States first described developmental disabilities by category as follows in the Developmental Disabilities Assistance and Bill of Rights Act (PL 94-103) of 1976. The categories of developmental disorders include mental retardation, autism, brain disorders, microbrain dysfunction, hyperactivity, learning disabilities, cognitive impairment, chronic encephalopathy, developmental imbalance, minimal neurological disorders, cognitive impairment, speech disorders, and dyslexia. Neurological disorders such as epilepsy, cerebral palsy, etc. A developmental disability is 'a persistent and essential disability caused by mental retardation, cerebral palsy, epilepsy, or autism that occurs before the age of 18'. If we look at the causes of developmental disabilities, there may be purely physical disabilities such as congenital visual and auditory impairments, and they appear due to cerebral palsy, epilepsy, autism, or other disability conditions. It can also be caused by chromosomal abnormalities such as Down syndrome, fetal alcohol syndrome, and weak syndrome.

In Korea, the term developmental disability was first used in public law when the category of disability was expanded in the "Welfare Act for Persons with Disabilities" in 1999 and the concept of disability was reconceptualized[7]. In Korea, the "Welfare Act for Persons with Disabilities" limited the developmentally disabled to those belonging to 'intellectual disability and autistic disorder' as a part of mental disability. The term 'intellectual disability' refers to a case where the IQ and sociality index are below 70, and 'autistic disorder' refers to autism in children and adolescents. In this study, 'person with developmental disabilities' was limited to 'intellectually disabled' and 'autistic disabled' according to the classification of the "Welfare Act for Persons with Disabilities", "Act on Guarantee and Support for Rights of Persons with Developmental Disabilities", and "Act on Special Education for Persons with Disabilities, etc.".

\subsubsection{Concept and Characteristics of the Intellectually Disabled}


The American Association on Mental Retardation (American Association on Mental Retardation) has changed the name of the association to the American Association for Intellectual Disabilities and Developmental Disabilities because the previously used name of 'mental retardation' may cause insults and misunderstandings to persons with disabilities and their families. on Intellectual and Developmental Disabilities) and used the name 'intellectual disability'. Korea also used the term 'intellectual disability' instead of 'mental retardation' in accordance with the "Welfare Act for Persons with Disabilities" amended on October 12, 2007. "Welfare Act for Persons with Disabilities" and "Act on Guarantee and Support for Rights of Persons with Developmental Disabilities" Intellectually disabled is defined as 'a person whose mental development is permanently retarded and whose intellectual ability development is insufficient or incomplete, and has considerable difficulty in handling his/her own personal affairs and adapting to social life'. In addition, the "Special Education Act for Persons with Disabilities, etc." defines 'mental retardation' as 'a person who has difficulties in educational achievement due to both intellectual intelligence and difficulties in adaptive behavior'. In other words, it can be seen that the term 'intellectually disabled' is used in the Social Welfare Act, and the term 'mental retardation' is still used in the Special Education Act. This study intends to define an intellectually disabled person as a person who develops a disability before the age of 18 and requires support in daily life, social life, and professional life due to limited intellectual function and ability to adapt to society.

People with intellectual disabilities have strong self-orientation, and due to lack of responsibility, social skills, concentration, memory, imitation learning ability, etc., their daily living ability and social adaptation ability are significantly reduced, and there are restrictions in interpersonal relationships and various social activities[8]. In order to understand the professional life of people with intellectual disabilities, it is necessary to understand their various characteristics first. The characteristics of the intellectually disabled by area are as follows.

First, in terms of physical characteristics, intellectually disabled people are not significantly different from non-disabled people in appearance. However, due to the dysfunction of the sensory organs due to the development of the brain, the function of the sensory organs is limited. Due to this, the structure of speech is not complete, and the meaning transmission is limited.

Second, in terms of psychological characteristics, the intellectually disabled show maladaptive behaviors such as aggressive tendencies or psychological atrophy due to their slow mental development and rejection of their surroundings. In addition, there is a strong tendency to be afraid of learning and to depend on others due to a sense of failure in continuous learning. This learned helplessness leads to weak will and lack of achievement[9].

Third, in terms of socio-emotional characteristics, it is difficult to use local community institutions due to the problem of adaptive behavior and the lack of various expressive abilities. In addition, they are not able to find activities suitable for personal interests on their own, fail to ask for help when necessary, and are inexperienced in terms of utilizing various leisure and recreational interests[10].

Fourth, although basic communication is possible in terms of linguistic characteristics, it is difficult to communicate smoothly due to the slow speed of language development. Therefore, it is effective to communicate if you select and use easy words or simple language structures instead of difficult words or sentences. People with moderate intellectual disabilities have very limited intellectual learning, so articulation disorders such as substitution and omission of sounds in speech and language domains frequently occur, and among them, language disorders including delayed oral development, limited vocabulary, and incorrect grammar use. It is common to have them[11].

Considering the characteristics of the intellectually disabled, the following should be considered when providing vocational support[12]. First, since it is difficult for people with intellectual disabilities to learn complex skills, the level of skills that people with intellectual disabilities can learn should be determined based on their abilities and needs, not on the general developmental level. Second, intellectually disabled people differ from non-disabled people in the amount and frequency of time for 
skill acquisition. Therefore, in general, the more severe the disability, the more attempts are required to teach them to reach a meaningful standard of a skill than non-disabled people. Third, compared to nondisabled people, the rate of forgetting skills acquired over a certain period of time is higher, and the time it takes to restore the forgotten skills to the original level is longer. Therefore, after completing vocational education, it is necessary to teach the skills necessary in the community to the intellectually disabled so that they can do well in their professional life in the community. Fourth, the level of transfer and generalization of learning is not high for intellectually disabled people compared to non-disabled people. It is difficult to apply the skills learned in vocational education to other environments. Therefore, what is important in the professional life of the intellectually disabled is that it is effective to educate them in the real world. Fifth, it is difficult for people with intellectual disabilities to synthesize and apply the knowledge they have learned. For example, non-disabled people can purchase items in a store by combining reading, counting, and speaking, but because it is difficult for people with intellectual disabilities to combine them and connect them, it is necessary to teach them specifically what is necessary for solving problems in a real environment.

\subsubsection{Concept and Characteristics of Autistic Disorder}

Amendment in Welfare Act for Persons with Disabilities In Korea[13] included 'autistic disorder' in the disability category. In the "Welfare Act for Persons with Disabilities" and "Act on Guarantee and Support for Rights of Persons with Developmental Disabilities", 'autistic disabled' is defined as 'in everyday life due to impairments in language, body expression, self-regulation, and social adaptation functions and abilities due to childhood autism and atypical autism. It is defined as a person who needs the help of others due to significant restrictions in social life In addition, the subject of special education with emotional disorders under the "Special Education Promotion Act"[14] firstly, has extremely poor academic performance even though there are no abnormalities in intellectual, physical or perceptual aspects, and secondly, has problems in interpersonal relationships with friends or teachers Third, those who exhibit inappropriate behavior or emotions under normal circumstances, fourth, those who live in an anxious and depressed mood, and fifth, those who experience physical pain or fear due to emotional disorders related to university or personal problems, and sixth, those with deficiencies in response to sensory stimuli, language, cognitive ability, or interpersonal relationships. The sixth of these refers to the characteristics of people with autism. However, in 2007, when the "Special Education Promotion Act" was reorganized into "Special Education Act for Persons with Disabilities, etc.", autistic persons with disabilities were divided into emotional disorders and separate disabilities. According to this law, a person with autism is defined as "a person who has deficits in social interaction and communication, and who needs help with educational achievement and adjustment to daily life because of limited and repetitive interests and activities".

Meanwhile, the term 'autism spectrum disorder' has been used to refer to children with various related characteristics. Autism is beginning to be understood as a continuum of 'autistic tendencies' rather than a clearly distinguished disorder. This is because this phenomenon reflects the reality that it is difficult to distinguish between a general defect and a unique defect unique to autism due to the wide variety of symptoms that occur with autism. In other words, it shows characteristics such as difficulties in interacting with others, defects in speech, language, and communication, persistence in the same environment, stereotyped behaviors or other self-stimulatory behaviors, and various abnormal behaviors toward sensory stimuli. People with autism often exhibit typical physical growth and development, but sometimes exhibit unusual skills, knowledge, and abilities. In particular, they have a wide range of intelligence levels and communication skills. In other words, all disorders classified as autism spectrum disorder show varying degrees of impairment in three aspects of communication skills, social interaction, and repetitive and stereotyped patterns of behavior[15]. 
People with autism are usually unable to relate basic information about themselves to their environment and what they have just done. They have particular difficulty answering open-ended questions such as why, what, where, how, and when. They also have difficulties in giving and receiving necessary words during a conversation. Autistic persons with autism are characterized by abnormal language transformation, including strange language rhythms, echoes, intonation invariability, and reversal. Each of these language modifications makes functional communication difficult in the workplace[16]. Also, people with autism do not have the ability to form typical social relationships due to lack of social skills. In an environment where they have to work in relationships with multiple people, they are only interested in the task assigned to them and prefer to spend time alone. And it can be problematic to retain employment, as unintentional actions can cause discomfort to co-workers.

\subsection{Professional Life of Persons with Developmental Disabilities}

In fact, for people with disabilities, occupations are the basis of economic independence, so regardless of the degree of disability, all people with disabilities are provided with an opportunity to discover the meaning of life through professional life. Work is more than a means of earning wages, it improves the quality of life and enhances individual identity and status.

The reason that professional life is important for people with developmental disabilities is that it not only increases earned income but also gives meaning to life as a productive human being. For this reason, all persons with disabilities, including those with developmental disabilities, are systematically educating for professional life from school age in order to achieve social cohesion through a smooth professional life. However, more important than these educational efforts is the will to get a job and the breaking down of barriers to entry into the job market. Compared to the past, the employment environment has been improved through policies related to the employment of the disabled, but other efforts for success in employment, job maintenance, and follow-up management are still lacking for the developmentally disabled.

Korea is making institutional efforts through the "Disability Discrimination Act" and "Employment Promotion Act for Persons with Disabilities" to ensure the professional life of the disabled. The "Employment Promotion Act for Persons with Disabilities" was created with the purpose of promoting employment, vocational rehabilitation and job stability of the disabled so that they can lead a humane life through a professional life that suits their abilities. Therefore, for the professional life of the disabled, not only the government and corporations but also all members of society must make sincere efforts to ensure the professional life of the disabled. Disabled people can have the pride of economic independence as a member of society by allowing them to live independently without being dependent on others through their professional life.

A variety of support is essential for people with developmental disabilities, who have many cognitive limitations, in order to have a smooth job life. AAIDD[4] emphasized wise support for the intellectually disabled, and said that such support can improve the functional ability of the intellectually disabled. Support here refers to efforts aimed at promoting a person's development, education, interests, and personal well-being, as well as resources and strategies to improve an individual's functioning. If these vocational supports are continuously managed, it will be of great help to the professional life of persons with developmental disabilities.

'Vocational Rehabilitation Facility', one of welfare facilities for the disabled in Korea's "Welfare Act for the Disabled", is defined as a facility that enables persons with disabilities who are difficult to work in a normal working environment to receive vocational training or live a professional life in a specially prepared working environment. Article 41 of the "Enforcement Rule of the Welfare Act for Persons with Disabilities" describes three types of 'vocational rehabilitation facilities' as follows. First, it is a workplace for the disabled. Provide vocational rehabilitation training programs such as vocational 
adaptation ability and job function improvement training to the disabled with low vocational ability, provide work opportunities under conditions that can be protected, and pay wages in return for the corresponding labor; or other competitive employment markets. Second, it is a workplace for the disabled. It is a facility that provides work opportunities to disabled people who have vocational skills but has difficulty finding employment due to mobility, accessibility, or social restrictions, pays wages above the minimum wage, and helps them move into a competitive job market. Third, it is a vocational adaptation training facility for the disabled

\subsection{Independent Life of Persons with Developmental Disabilities}

\subsubsection{The Concept of Independent Living}

Disability is not seen as an individual's physical or mental impairment or functional limitation, but is beginning to be recognized as a result of the interaction between these individual obstacles and the social environment surrounding the disabled. It was seen that maladaptation or problems of the disabled occurred in an inappropriate socio-cultural environment. This position of defining disability has shifted from a traditional approach to a new independent living approach. In other words, the traditional approach that people with disabilities are viewed as incompetent has changed to an independent living approach that views people with disabilities as people who can control and make decisions about their lives.

The independent living approach is contrary to the traditional methods of existing welfare service providers for the disabled, under the assumption that the disabled can lead and control their own life, make choices in important life decisions, and take responsibility for all services. It can be seen as an approach that helps people with disabilities make choices and make decisions for themselves at important moments in their lives[17].

The key to independence of persons with disabilities is 'guaranteeing the right of persons with disabilities to choose'. The ultimate purpose of independent living is to realize an independent life with the right to self-determination and the right to choose one's own life[18]. In order to guarantee these options, political and economic rights must be guaranteed through professional life. The The meaning of concept of independent living can be summarized as shown in [Table 1].

[Table 1] The Meaning of Concept of Independent Living

\begin{tabular}{|c|c|}
\hline $\begin{array}{c}\text { The important concept of Independent } \\
\text { Living }\end{array}$ & Meaning of concept \\
\hline Disability & A result of the interaction between these individual obstacles and the social \\
environment.
\end{tabular}

\subsubsection{Independent Living Support Model}

In order to understand the professional life of workers with developmental disabilities, it is necessary to understand the background and concept of the emergence of social models and independent living support models, and their relevance to professional life. To this end, after comparing the medical model and the social model, the emergence of independent living support model will be examined.

\subsubsection{Medical and Social Models}

The 'medical model', which had dominated until 1990, established a paradigm for the disabled as the 
incompetent weak and patient, and for the family of the disabled as the victim of social stigma, prejudice, and hurt. This approach defines disability as a 'property of the individual body' rather than the social environment, and is concerned with the causes, diagnosis, prevention and treatment of physical, sensory and cognitive impairments[19]. It expects them to adapt to their damage. This view can be said to be Ableist, which views disabled people as inferior beings. The social model points out the problem of the social system that alienated the disabled from the main environment. The Association for Physical Disability defines disability as a social barrier imposed by a society that does not tolerate people with disabilities. The social model of disability is not an individual's impairment or adaptation, but socially imposed barriers: inaccessible buildings, limited modes of transportation and communication, and prejudiced attitudes, which relate disability to a subordinate social position and It consists of low-valued life experiences[20]. This model was first articulated by disability activists in England in the early 1970s. It also had a real impact on the thinking of disability activists and academics in the United States, who saw the removal of such barriers as a matter of civil rights that must be protected by law[21].

In order for people with developmental disabilities to adapt well to the local community, efforts should be made to ensure job security so that they can lead a productive life in society. It is necessary to prevent alienation from society through this professional environment and consideration. Ronald Mays of the United States called universal design to design so that all people can use products, architecture, environment, and services more conveniently and safely, regardless of disability or age. Just as the special education world is currently considering a universal design in terms of education so that all people can be educated, it is time to prepare a universal design that allows access to jobs that fit the social model in the social welfare dimension. The coparison of definition of disability with medical modle and social modle can be presented as shown in [Table 2].

[Table 2] The Coparison of Definition of Disability with Medical Modle and Social Modle

\begin{tabular}{|c|c|c|}
\hline & Medical Model & Social Models \\
\hline Definition of disability & disability as property of the individual body & disability as a social barrier imposed by a society \\
\hline $\begin{array}{c}\text { Main problem of } \\
\text { disability }\end{array}$ & Individual hancicaps & Social systems \\
\hline Viewpoint of the disable & Inferior beings & Subject of civil rights \\
\hline
\end{tabular}

\subsubsection{Rehabilitation Model, Independent Living Model, and Independent Living Support Model}

In order to understand the professional life of people with developmental disabilities, it is necessary to understand the independent living support model first. For this, the related model can be organized as follows. First, since the rehabilitation model sees the main responsibility of disability as the disabled person, it is believed that disabled people must obey the instructions and advice of experts such as doctors and vocational rehabilitation counselors dependently. It is concerned with professional intervention rather than individual choice and will. On the other hand, the independent living model identified the disabled as the socially underprivileged and raised the problem that the resources and opportunities to be enjoyed as members of society were blocked.

Whereas the rehabilitation model regards services as being expert-centered, the independent living model focuses on the self-selection and decision-making rights of persons with disabilities. Here, the disabled people'sism seeks the welfare of the disabled based on human rights that emphasizes the rights, choice and evaluation of the disabled by criticizing and checking the unequal power relationship between the society, environment, and service supply system that oppresses the disabled through political solidarity with the disabled. As a result, it can be defined as a developed rights movement led by persons with disabilities to achieve the rights of persons with disabilities, integration, independence, self-help and self-determination[22]. In both models, the main problem of disabled people is not the 
disabled person but the expert-client dependent relationship and the social control environment

Second, the independent living model believes that the cause of the problem lies in the social environment, not the disabled person, so it can be solved through social reform and environmental change. Independent living is a Paradigm Shift in the belief that the fundamental cause of all problems experienced by people with disabilities is from the irrationality of society, from what it used to be believed that all problem factors were present in the disabled. Therefore, through social integration, it aims to practice independent life of self-management and improve social values to defend the rights of the disabled and to have consumer sovereignty.

Third, the independent living support model places importance on role sharing and cooperation between experts and persons with disabilities. This is because, in the case of independent living of persons with developmental disabilities, which requires the support of experts or their families, cooperation and practical meaning are more important before discourse on the initiative of the person concerned.

\section{Conclusions}

This study focused on domestic and foreign literature and related reports on the professional life of persons with developmental disabilities. In detail, the research purpose was achieved by dividing the thesis into degree claim thesis, other research thesis, and policy report by the researcher to read, organize and analyze the contents. Most of the workers with developmental disabilities who need support in terms of vocational and communication skills are working in protective employment in protective workplaces. These efforts should be accompanied by a literature understanding of the characteristics of people with developmental disabilities and the necessity of professional life. Through various literature reviews, the following conclusions can be drawn.

First, developmental disabilities are those that have neurological conditions closely related to intellectual disabilities, such as intellectual disabilities, cerebral palsy, epilepsy, autism, and learning disabilities, or have problems requiring education and training similar to those required for intellectual disabilities. say In other words, 'mental, physical, or both present before age 22 that persist indefinitely and result in substantial functional limitations in three or more areas of life activity (personal processing, language, learning, mobility, self-management, independent living, and economic self-sufficiency). It is a severe and chronic disability caused by However, in Korea, 'developmental disabilities' were limited to 'intellectually disabled' and 'autistic disabled' according to the classification of the "Special Education Act for Persons with Disabilities, etc".

Second, for people with developmental disabilities, the meaning of professional life is to lead an independent life in society or as a way of expressing the value of one's existence. People with disabilities should live with non-disabled people as well as fulfill their social roles, work according to their abilities and aptitudes, and enjoy opportunities for self-realization through 'vocational activities' [23]. The reason that professional life is important for people with developmental disabilities is that it is not only increases earned income but also gives meaning to life as a productive human being.

Third, in order to understand the professional life of workers with developmental disabilities, it is necessary to understand the background of the emergence of social models and independent living support models. The social model points out the problem of the social system that alienated the disabled from the main environment. The Association for Physical Disability defines disability as a social barrier imposed by a society that does not tolerate people with disabilities. And the independent living support model places importance on role sharing and cooperation between experts and persons with disabilities. The limitation of this study is that the conclusions are presented mainly from domestic papers. The resrech on literature review, including overseas papers, should be conducted with a focus on recent papers. 


\section{References}

[1] 2016 Survey on Employment Status of Persons with Disabilities, Korea Employment Development Institute for the Disabled, (2016)

[2] M. O. Kim, D. H. Kim, A Study on the Factors Affecting Life Satisfaction among People with Developmental Disabilities, Disability \& Employment, (2015), Vol.25, No.2, pp.209-233, DOI: 10.15707/disem.2015.25.2.009

[3] K. S. Oh, Theory and Practice of Social and Psychological Evaluation of the Disabled, Vocational Rehabilitation Referencesersons with developmental disabilities, disability and employment, (2015), Vol.25, No.2, pp.209-233.

[4] Consotitium for Citizen with Didabilities, Association on Intectual and Developmental Disabilities, (2010)

[5] Glossary of Special Education Terminology, National Institute of Special Education, (2009)

[6] S. H. Lee, H. J. Cho, Ewview on the Concepts of Developmental Disabilities in Special Education, The Journal of the Korean Association on Developmental Disabilities, (2001), Vol.5, No.2, pp.17-30.

[7] B. N. Shin, Cultural Technical Journal on the Professional Life of Persons with Developmental Disabilities, Gangnam University, Doctoral Dissertation, (2014)

[8] M. H. Kim, The Effect of Adults with Intellectual Disabilities' Daily Living Ability (IADL) and Residence Type on the Support Burden of Parents and Families-Focused on Yeongdong, Gangwon-do, Sogang University, Master's thesis, (2010)

[9] G. Dawson, D. Hill, A. Spencer, L. Galpert, L. Watson, Affective exchanges between young autistic children and their mothers, Journal of Abnormal Child Psychology, (1990), Vol.18, No.3, pp.335-345, DOI: 10.1007/BF00916569

[10] N. S. Kim, K. S. Kim, The Analysis of majoring course curriculum in school for students with mental retardation, Journal of Intellectual Disabilities, (2006), Vol.8, No.3, pp.243-259, UCI: G704-000501.2005.21.3.001

[11] E. H. Back, U. H. Na, An Analysis of Cognitive and Metacognitive Instruction Research Studies from 1997 to 2004 , JOURNAL OF EMOTIONAL \& BEHAVIORAL DISORDERS, (2005), Vol.21, No.3, pp.101-126.

[12] W.Y. Kang, W. H. Na, K. S. Park, J. J. Ryu, M. H. Jung, D. J. Kim, S. W. Jung, Y. J. Kang, Introduction to Vocational Rehabilitation, House of Sharing, (2009)

[13] Amendment in Welfare Act for Persons with Disabilities, National Legal Information Center, (1999)

[14] Special Education Promotion Act, National Legal Information Center, (1977)

[15] Y. T Kim, Comparative study of the phonological processes between the normal and the articulation-disordered children, Journal of Special Education, (1995), No.12, pp.211-235.

[16] K. W. Lim, A Qualitative study on opinions of experts about vocational rehabilitation related factors for individuals with Autistic spectrum disorders, Journal of Vocational Rehabilitation, (2011), Vol.21, No.3, pp.43-70.

[17] M. S. Chung, H. T. Yang, The Welfare Theory of the Disabled, Minsa Jeong, (2013)

[18] H. A. Go, The Effect of Disability Identity and Coping Efficacy on Independent Living of Disabled Persons Discharged from Facilities, Baekseok University, Doctoral Dissertation, (2016)

[19] Tobin Siebers, Disability theory, University of Michigan Press, (2009)

[20] S. H. Park, What is a Disability, Hakjisa, (2016)

[21] M. Oliver, The politics of Disability, Critical Social Policy, (1984), Vol.4, No.11, pp.21-32.

[22] K. I. Kim, The Significance and Issues of the Enactment of the Act on the Prevention of Discrimination against Persons with Disabilities by Parties, Monthly Welfare Trend, (2005), No.86, pp.29-33, https://www.dbpia.co.kr/journal/articleDetail?nodeId=NODE01140666

[23] G. O. Lee, A Case Study on the Performance of Office Assistant Organization in Adults with High Functioning Autism, Daegu University, Master's thesis, (2008) 